\title{
The Role of Information Resource Planning in the Logistics Management of Electric Business
}

\author{
Jinying Li \\ School of economics and management \\ North China Electric Power University \\ Bao ding, China \\ dlijinying@sina.com
}

\author{
Tao Pan \\ School of economics and management \\ North China Electric Power University \\ Bao ding, China \\ pt5542341@163.com
}

\begin{abstract}
The task of information resources planning is to solve the planning and coordination of information resources related to application projects. This work can share the data resources in the maximum extent, and reduce data redundancy. This article discusses the existing problems, and we use data analysis and practical investigation to research the role of information resource planning in logistics enterprises. Puts forward the solution based on the relevant theory of information resources planning according to the current situation of China's logistics management. The innovation is that we draw structure diagram of the information resource planning, and detailed the exposition, and describe the details of the structure diagram.
\end{abstract}

Keywords-E-commerce, logistics, rookie network, information resource planning, synergy

\section{INTRODUCTION}

The fundamental purpose of modern logistics is to improve the efficiency of logistics, reduce the cost of logistics, and meet the needs of customers. It shows the development trend of information, networking, automation, intelligence, standardization, Among them, the information is the core of modern logistics ${ }^{[1]}$. In the process of logistics information construction, there are a lot of logistics information and related information, which is one of the most important resources of enterprises. The development of enterprise logistics information resources is the core task of logistics information construction, and the development of logistics information resources is not only the starting point of logistics information, but also the end result of logistics information ${ }^{[2.3]}$. Many companies ignore the work of information resource planning, there is no clear information demand, lack of standardization, information resources can't be shared, information systems can't be interoperable, so the result is the enterprise can't enjoy the benefits from information investment, which seriously hindered the process of logistics management information ${ }^{[4]}$. As the main way to eliminate the "information island", integrate information resources and realize the sharing of information resources, information resources planning is the key to the construction of logistics information.

\section{Present Situation of Logistics Development in China}

\section{A. Development Present Situation}

Freight logistics in China has now become a major industry, it has formed a huge industrial chain, and it is a sign of the times, the development of the logistics industry every year will hit a new high, and more and more enterprises began to focus on the development of logistics. But there are also a big problem in the logistics enterprises: the logistics enterprise information level is low. From the perspective of information construction, China's logistics enterprises are still in a primitive stage relatively ${ }^{[5]}$. According to statistics, those enterprises that has been implemented or part of the implementation of information technology enterprises accounted for only $21 \%$, the full implementation of information technology enterprises is only $10 \%$. In the supply chain of the entire industry, the information flow between the upstream and downstream of the enterprise closed, resulting in high cost of circulation ${ }^{[6]}$. This is because of the low level of logistics enterprise information construction, resulting in poor information. Due to the lack of overall planning and unified information standards, so the design, production and management information can't be fast circulation, and can't be shared, resulting in a serious digital divide problem, many information islands were formed.".

\section{B. Rookie Network}

In 2013, the Alibaba established rookie network with SF, Zhongtong, ShenTong, Yuantong and rhyme, it marks the electricity supplier logistics enterprise get a key step to information. The rookie network use advanced Internet technology to build an open, transparent and shared data application platform. It provide quality services for ecommerce companies, logistics companies, warehousing companies, third party logistics service providers, supply chain service providers and other types of enterprises, the most important is that it can support the logistics industry develop to high value-added areas. In the end, it can establish a social resource efficient cooperative mechanism to enhance the quality of China's social logistics services, build China's future commercial infrastructure ${ }^{[7]}$. The construction of China intelligent backbone network will help local economic development and industrial upgrading, accelerate the process of urbanization, improve the level of national economic 
information. Chinese intelligent backbone network not only continue to improve the logistics information system, but also construct modern logistics and warehousing network throughout the country based on existing national highway, railway, airport and other transportation infrastructure layout and planning, improve the social efficiency of logistics and infrastructure utilization. It open to all manufacturers, network operators, express logistics company and the third party service company. So in essence, the rookie network carry out the integration of information resources of e-commerce, consumer, third party service (the logistics enterprise ). So that consumers can make more comfortable shopping, business enterprises can accurately grasp the consumer's propensity to consume, third party service providers to provide more efficient services. Rookie network has just been established, then the information resource planning in the rookie network should play a huge role.

\section{AN OVERVIEW OF INFORMATION RESOURCE PLANNING}

\section{A. The Basic Idea of Information Resources Planning}

As human resources, material resources, financial resources and natural resources, Information resources is an important resources for the enterprise. We should manage information resources like we manage other resources. Information resources management(IRM) is a necessary part of enterprise management, it should be included in the budget of enterprise management. IRM contains data resource management and information processing management. Data resource management emphasizes the control of data, the later emphasizes the importance of how to get and process information under a certain condition, and it also emphasize the importance of enterprise information resources. IRM is a new function of enterprise management, and the reason for this new function is the explosion of information and document information, and the urgent demand for the management of all levels to obtain the ordered information also prompted the generation of functions. The goal of IRM is to improve the efficiency of management by enhancing the ability of the enterprise to deal with the internal and external information demand under the condition of dynamic and static conditions. In order to achieve high efficiency, effectiveness and economy, the best effect, it also known as the principle of $3 \mathrm{E}$, the three closely related to each other.

\section{B. The Importance of Information Resources Planning}

The establishment of information system is a gradual process (now and in the future will be the case), it often lack of top-level design and unified information standard, resulting in poor flow of information, and the information can't be shared. Form "information isolated island" and "application island". It can't maximize the benefits of information technology investment. Information resource planning can effectively eliminate the "information island" in the process of enterprise information ". At present, many enterprises have established a production automation control system and management information system of information network, Because every department development their own system ,lack of overall planning and unified information standard, resulting in the design of production and management information can't be fast circulation, formed many information islands. the degree of information sharing is very low, causing a serious waste of information resources. It can not play the benefits of information technology investment.

At present, the logistics enterprise is in the situation, various courier companies in different degree built their own information systems, electronic commerce also has its own data management system, such as Alibaba have their own Skynet data system, responsible for tracking sales statistics, a variety of merchandise sales, and even some of the larger shops will have their own a set of small information resource management system. But almost there is no sharing among these information systems, they are operation independently. if we combine these data with each other, then the benefits are immeasurable. We should put the information resource planning as the basic information, so the information can be shared in the greatest extent, and ensure that each department production information to other departments, greatly enhance the enterprise information sharing and utilization.

\section{The Method of Information Resource}

\section{1) Three kinds of organization methods}

- From top to bottom. From the point of view of the user's application requirements, we can analysis the problem that the user wants to solve according to what BI, thus we can summed up what the user needs to get knowledge from the BI system, then we can launch the BI information system architecture and data architecture.

- $\quad$ From bottom to top. We start from the existing data resources, analyze the data resources that users can get, then conclude the data architecture of BI system, and then introduce the information system structure and knowledge architecture of BI.

- Up and down combined. We should not only consider the data resources that users can get, but also consider the application requirements of user services to the BI system. For electric business logistics enterprises should adopt the method of combining up and down.

\section{2) Engineering method}

Information resource planning has two stages: requirement analysis, system modeling. Three models: function model, data model, structure model. Its method is shown in Fig. 1.

\section{- $\quad$ Requirement analysis}

The first phase of information resources planning is the demand analysis, including the function of the demand analysis and the demand for data analysis. Functional requirements analysis contains the definition of functional areas, the definition of business process and business activities analysis. According to the principles of information resource planning for global domain functions in information engineering methodology, The competent leadership and business analysts are divided all areas of management into several functional areas based on logical relationships of various operations. Then we need to find out the whole 
business process of each functional area, and the last step is to segment the business process into some business activities. Data demand analysis is the most important, the maximum workload and complex analysis of information resources planning. It requires investigate the information of all management needed, which includes user view analysis, data element analysis and data flow analysis. Data analysis need to start from the investigation of the user view, It requires close cooperation between the two types of people. And analysis the information needs of the business management level carefully.

\section{- $\quad$ System modeling}

System modeling refers to the establishment of the system model based on the analysis of the requirement of standardization, which is the core and key work of the information resource planning. It includes function model, data model and system architecture model. System function modeling based on requirement analysis and business process reengineering, which is composed of logical subsystem, function module and program module. System data modeling is to solve the problem of "information organization" of the system. It is the core of the information resources planning, and it is the fundamental guarantee for the reconstruction of the data environment. The basic work of data modeling contains: firstly, the definition of business topics, the user view grouping is defined as the entity group according to the theme, and conceptual data model; Secondly, we should analyze the attributes of the entity according to the business needs, normalized data structure, generate the basic table, and put forward the logical data model; The last is the standardization of data elements, and further review the composition of the basic table. System architecture modeling is the relational structure of system data model and function model, which is represented by C-U matrix. It has an important role in the development of control module and the construction of shared database. The system architecture is divided into the global system architecture model and system structure model, the former indicates the relationship between the whole planning scope and the subject database, the latter represents the association of all the functional modules of a subsystem with the underlying table.

\section{The Role OF INFORMATION RESOURCES PLANNING IN THE ELECTRIC BUSINESS LOGISTICS}

Information resources planning is not only an independent Department of information resources planning, often involving multiple departments of different business areas (multi-level multi sector). For example, the courier company's various outlets and the provincial company have information exchange, information exchange also needed between the provincial companies, logistics companies and electricity suppliers also have a regular exchange of data, in order to grasp the market dynamics. Business and management of these sectors is relatively independent, but also need to contact each other, Therefore, these departments need to coordinate with each other, We need to carry out the organic combination and joint management of the information resources planning results of these departments. So we want to study the collaborative planning of information resources among business logistics enterprises, and rookie network will combine the courier company and electricity suppliers, what the rookie network want to do is a collaborative planning information resources.

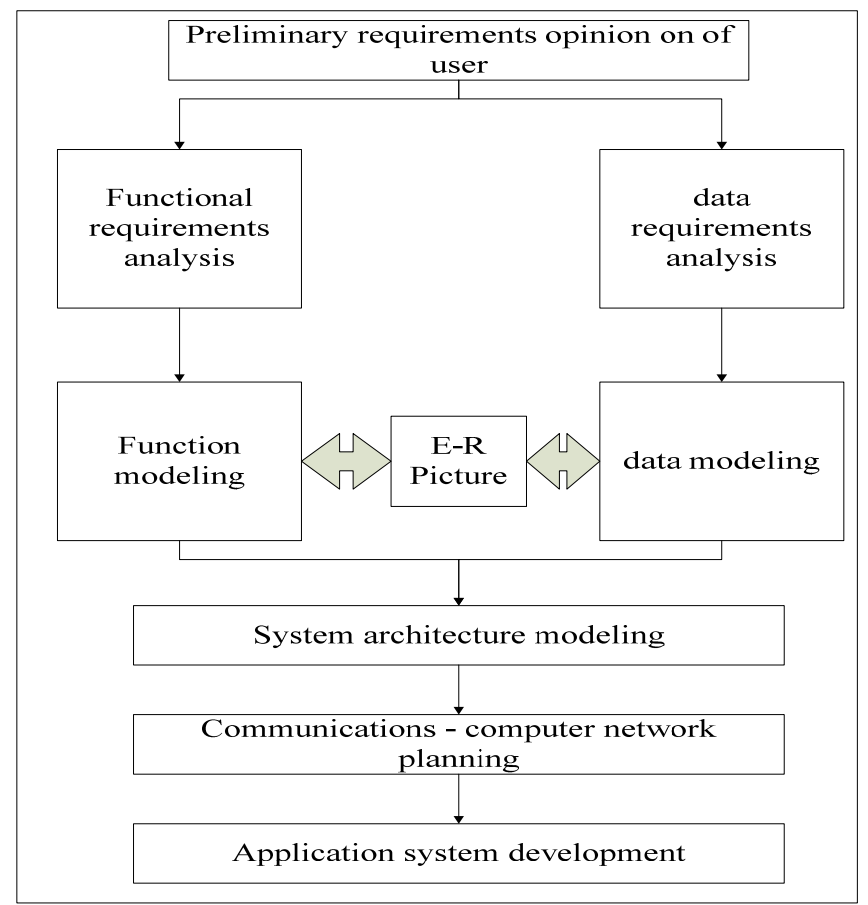

Fig. 1. System structure model

\section{A. Organization Mode of Collaborative Planning}

The first step of collaborative planning is to determine the organizational structure of the planning, namely, the organizational structure of the planning. Including the organization of planning and how to organize these units to organize effective planning activities. The structure diagram is shown in Fig. 2

- Branch: it is the smallest unit of information resources planning, It is generally a practical business department in the planning organization, which has relative independence. in this case, the main branch of the Department is the logistics branch. Its main work is to carry out the information collection and planning of the department. At the same time, it also carry out collaborative planning with the intermediate sector.

- Intermediate sector: the secondary unit of information planning. It is a running unit with various functions in the organization, which has strong independence and coordination. Provincial logistics company is the middle department. Their main duties are to report branches under the information resources integration and optimization, remove redundant data, and report to departments, also guide the various branches of work division.

- Summary Department: it is built on the central branch of the planning unit. It is a summary of the results of the central branch of the planning unit, an actual business sector can be a branch department, an the 
same time it also can be a summary of the department, Summary of the work of the Department is carried out on the overall coordination and optimization, there is a strong global.

- Other planning organizations: the unit is in parallel with the summary department. They exchange share information equally. In this case, each logistics company is a planning organization, their information exchange and mutual, finally converge in data processing center .

- Data processing center: This is the core of the entire collaborative planning. All data of Logistics, and electricity suppliers joined all in the data processing center, analysis data from all aspects, and then return the results to the various branches, to help them better develop the company plans to adjust.

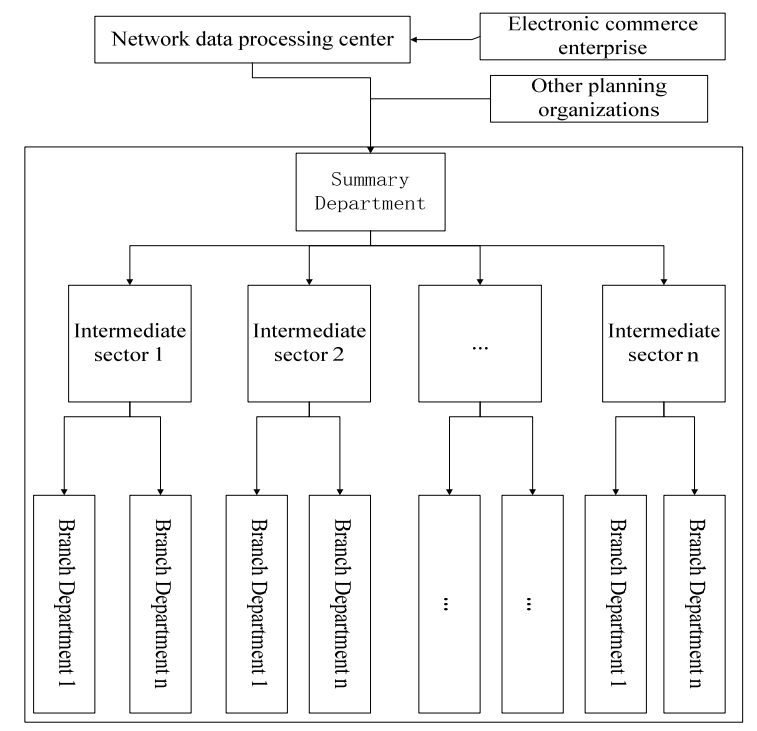

Fig. 2. Collaborative planning structure diagram

\section{B. Cooperative Mode}

After determining the planning unit, we need to determine the relationship between the various units. In the planning organization, there is a relationship between the Department and the branch department, which includes the superior and the subordinate. In order to avoid the relationship is too complicated, the membership relation is established through the summary department. Various planning organizations still exist in the same level of aggregation. In summary, the planning department can take the "two vertical and three horizontal" collaborative planning. "Two vertical" refers to two vertical synergy. One refers to the vertical coordination between central department and the branch, the other one is the vertical collaboration between the summary department and the Central Department. "Three horizontal" refers to the three horizontal synergy, the first refers to the horizontal synergy between two planning organizations. The second refers to horizontal synergy between the electric business and data processing center. The third refers to horizontal coordination between the logistics enterprise and data processing center. "Two vertical and three horizontal" collaborative approach will coordinate different business areas of the planning unit, work together to accomplish the multilevel and multi sector information resource planning, achieve the goal that the unification of the upper and lower, horizontal through, the shared results. form a complete and unified information resource planning system.

\section{Coordination Among Other Planning Organizations}

In the picture above, there are some operation between small organizations that are not labeled. For example, the exchange of information also exist in the various branches and the central authorities, Electronic commerce also has the information exchange, even the electronic commerce and the material flow also can carry on the direct information exchange. The exchange of information on the information resources planning also has a certain role, we should also pay attention to it. But we must realize that the more up we go, the more important the information resources planning is. So, in the information resource planning, we should have the overall situation, grasp the overall rhythm from the overall situation.

\section{SUMMARY}

This paper describes the significance of the information resource planning, the importance of the method, the collaborative planning of multi sectoral information resources in e-commerce logistics is discussed in detail in this paper. These methods are close to the needs of the information resources planning under the current logistics management system. this paper also have some guidance and reference to the establishment and development of logistics enterprises and other departments such as the government or large enterprises.

\section{ACKNOWLEDGMENT}

This work was supported by "the Fundamental Research Funds for the Central Universities (2014ZD21)" and "Beijing Higher Education Yong Elite Teacher Project(YETP0709)"

\section{REFERENCES}

[1] Zhang Tingwei. Planning theory as a system innovation theory planning theory and the theory of the direction of the development of the nonlinear theory of the trajectory of the [J]. urban planning, 2005 (8): 918

[2] Wu Jin. Modern system science method and application optimization method and complexity [M]. Chengdu: University of Electronic Science and technology of China Press, 182-196 2005.

[3] Huang Tiyun, Li Li. Management information system [M]. Beijing: Higher Education Press, 2000.

[4] Song Pingping. Preliminary study on Enterprise Information Resource Planning [J]. Intelligence journal, 2003 (5): 11-8.

[5] Wu Jianhong. Information resource planning in the process of enterprise information $[\mathrm{J}]$. Journal of Xi'an University of Posts and Telecommunications, 2004 (4) .

[6] Zhang Guirong. Modern enterprise information resource management mode and content $[\mathrm{J}]$. modern information, 2005 (7).

[7] Liu Feichi. Some bottleneck problems in the development of logistics informatization [J]. logistics science and technology, 2006 (3): 41- 42 